\title{
PEMBERDAYAAN MASYARAKAT MELALUI “PROGRAM JAMBAN SEHAT" UNTUK PENINGKATAN KESEHATAN LINGKUNGAN
}

\author{
Iskandar $\operatorname{Arfan}^{1 *}$ \\ Lukas Diono ${ }^{2}$ \\ Tri Eko Sumarto ${ }^{3}$ \\ Lilik Yuniarsih4 \\ M.Idris 5 \\ Subardi 6 \\ Zakaria $^{7}$ \\ 1,2,3,4,5,6,7 Universitas Muhammadiyah Pontianak, Pontianak, Indonesia

\section{Iskandar.arfan@unmuhpnk.ac.id ${ }^{1 *}$ \\ 191510113@unmuhpnk.ac.id ${ }^{2}$ \\ 191510116@unmuhpnk.ac.id ${ }^{3)}$ \\ 191510120@unmuhpnk.ac.id ${ }^{4)}$ \\ 191510121@unmuhpnk.ac.id ${ }^{5)}$ \\ 191510126@unmuhpnk.ac.id ${ }^{6}$ \\ 191510130@unmuhpnk.ac.id7)}

Kata Kunci: [Jamban sehat, Pemberdayaan, Kesehatan

Lingkungan]

\begin{abstract}
Abstrak: Desa Sukabangun Dalam merupakan salah satu Desa yang ada di Kecamatan Delta Pawan Kabupaten Ketapang, Provinsi Kalimantan Barat. Secara geografis, Desa Sukabangun Dalam memiliki luas wilayah $2.310,5 \mathrm{ha} / \mathrm{m}^{2}$ dengan topografi berupa dataran rendah seluas $10 \mathrm{ha} / \mathrm{m}^{2}$ dan aliran sungai seluas $8 \mathrm{ha} / \mathrm{m}^{2}$. Masalah kesehatan masyarakat di Desa Sukabangun Dalam yang teridentifikasi meliputi tingginya kejadian Rumah tidak memiliki tempat Pembuangan akhir tinja (Septik Tank) dan jamban sehat (37\%). Hal ini dapat meningkatkan risiko penyakit berbasis lingkungan. Target kegiatan adalah penerapan IPTKES melaui kegiatan program jamban percontohan sehingga dapat dipergunakan sebagai sarana pembuangan tinja keluarga. Pelaksanaan kegiatan dilakukan bertahap, dimulai dari pendataan jamban sehat keluarga, penyuluhan mengenai jamban sehat, melalui Praktek Belajar lapangan berbasis Kuliah Kerja Usaha, pelaksanaan tabungan jamban (tanjan) dan komitmen bersama melakukan renovasi jamban umum desa menjadi jamban percontohan.
\end{abstract}

Published by:

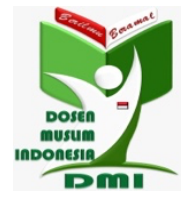

Copyright (C) 2021 The Author(s)

This article is licensed under CC BY 4.0 License

(cc) BY

https://dmi-journals.org/jai 


\section{Pendahuluan}

Sejalan dengan paradigma sehat, pembangunan kesehatan sekarang lebih ditekankan pada upaya preventif dan promotif termasuk upaya penyehatan lingkungan dan peningkatan perilaku hidup bersih dan sehat kepada masyarakat yang mempunyai daya ungkit yang besar dalam meningkatkan derajat kesehatan masyarakat. Dengan tidak meninggalkan upaya pengobatan dan rehabilitasi.

Untuk melaksanakan upaya-upaya tersebut maka dalam kebijakan dan strategi pembangunan kesehatan menuju Indonesia Sehat 2010. Pemerintah mengarahkan peningkatan kesadaran, kemauan dan kemampuan hidup sehat bagi setiap orang agar terwujud derajat kesehatan masyarakat yang optimal melalui terciptanya masyarakat, bangsa dan negara Indonesia yang ditandai oleh penduduknya hidup dalam lingkungan dan perilaku sehat, memiliki kemampuan untuk menjangkau pelayanan kesehatan yang bermutu secara adil dan merata, sert memiliki derajat kesehatan yang optimal.

Berdasarkan Profil Kesehatan Indonesia tahun 2020 Persentase keluarga dengan akses terhadap fasilitas sanitasi yang layak (jamban sehat) di Indonesia tahun 2020 adalah 87,5\%. Provinsi dengan persentase tertinggi keluarga dengan akses terhadap fasilitas sanitasi yang layak (jamban sehat) adalah DI Yogyakarta (100\%), Sulawesi Selatan (99\%), dan Kepulauan Bangka Belitung (97\%). Provinsi dengan persentase terendah adalah Papua Barat (29\%), Papua (34\%), dan Maluku (67\%).

Sarana jamban sehat dapat diklasifikasi menjadi jamban sharing/komunal, jamban sehat semi permanen (JSSP), dan jamban sehat permanen (JSP). Jamban sharing/komunal merupakan jamban yang digunakan bersama dalam masyarakat (pengguna lebih dari satu keluarga). JSSP belum menggunakan konstruksi leher angsa tetapi memiliki tutup dan terletak di dalam rumah. JSP adalah jamban yang sudah menggunakan konstruksi leher angsa dan terletak di dalam rumah. Pada tahun 2020, 72,3\% keluarga di Indonesia sudah menggunakan JSP. Sisanya 18,5\% menggunakan JSSP dan 9,2\% menggunakan jamban sharing/komunal. (Profil tahun 2020. Kemenkes RI, 2021).

Fokus pelayanan kesehatan masyarakat yang lebih bersifat promotif, preventif dan protektif memiliki tujuan agar frekuensi penyakit berkurang atau dengan diciptakannya peraturan - peraturan yang medukung upaya kesehatan. upaya dengan sasaran masyarakat ini dilakukan dengan prinsip pemberdayaan masyarakat agar terjadi perubahan di masyarakat dalam mendaggapi dan mengatasi suatu masalah kesehatan mengenai jamban sehat.

Upaya program kesehatan yang dilaksanakan harus sesuai dengan situasi dan kondisi daerah setempat dan diharapkan dapat mengatasi masalah-masalah kesehatan secara efektif dan efisien. Tenaga kesehatan sebagai sumber daya manusia diharapkan mampu melakukan usaha-usaha pembangunan kesehatan tersebut serta menepatkan peran serta serta masyarakat sebagai hal utama tenaga kesehatan dituntut mampu mengkreasikan antara teori-teori yang dimiliki dengan kondisi yang ada di masyarakat, untuk menyelesaikan masalah kesehatan, agar tercapai peningkatan derajat kesehatan masyarakat yang optimal.

Desa Sukabangun Dalam merupakan salah satu Desa yang ada di Kecamatan Delta Pawan Kabupaten Ketapang, Provinsi Kalimantan Barat secara geografis, Desa 
Sukabangun Dalam memiliki luas wilayah 2.310,5 ha/m^2 dengan topografi berupa dataran rendah seluas $10 \mathrm{ha} / \mathrm{m}^{\wedge} 2$ dan aliran sungai seluas $8 \mathrm{ha} / \mathrm{m}^{\wedge} 2$. Ketinggian wilayah dari permukaan laut adalah 2-5 mdl. Desa Sukabangun Dalam memiliki curah hujan 3091.7 Mm dan suhu rata- rata harian $25-35^{\circ} \mathrm{C}$.

Berdasarkan profil Desa Sukabangun Dalam, kesadaran dalam aspek pendidikan masyarakat didesa Sukabangun Dalam masih rendah, dikarenakan kondisi desa yang jauh dari kecamatan. Sehingga angka pengangguran di Desa Sukabangun Dalam cukup tinggi. Untuk aspek kesehatan Desa Sukabangun Dalam termasuk wilayah kerja Puskesmas Sukabangun. Desa Sukabangun Dalam juga telah memiliki Puskesmas Pembantu (PUSTU), posyandu serta kader posyadu desa (Profil Puskesmas Sukabangun 2020).

Pada proses analisa situasi kesehatan masyakarakat dilakukan dengan menganalisis data sekunder laporan dari puskesmas sukabangun dan bidan desa serta dilakukan survey cepat. Masalah kesehatan masyarakat di Desa Sukabangun Dalam yang teridentifikasi meliputi tingginya kejadian Rumah tidak memiliki tempat Pembuangan akhir tinja (Septik Tank) dan akses jamban sehat.

Berdasarkan data yang diperoleh pada bahwa yang menjadi masalah di Desa Sukabangun Dalam Kecamatan Delta Pawan Kabupaten ketapang adalah kepemilikan jamban. Masalah kepemilikan jamban, dimana dari 100 rumah tangga yang ada di Desa Sukabangun Dalam terdapat 37 rumah tangga (37\%) yang tidak memiliki jamban dan 63 rumah tangga (67\%) yang memiliki jamban.

Berdasarkan identifikasi masalah di atas, maka yang menjadi prioritas masalah adalah kepemilikan jamban. Hal ini didasarkan atas beberapa pertimbangan yaitu besarnya masalah (Magnitude), pentingnya jalan keluar dalam mengahadapi masalah (Importancy), kecepatan mengatasi masalah (Sensitifitas), dan efesiensi yang dikaitkan dengan biaya (Cost).

Dari prioritas masalah tersebut, maka intervensi yang dapat dilakukan berupa intervensi fisik dan non fisik. Intervensi fisik berupa pembuatan jamban percontohan, sedangkan intervensi non fisik berupa sosialisasi tentang pentingnya jamban.

Dengan demikian maka kegiatan ini diharapkan dapat membantu menyelesaikan masalah yang berkaitan dengan kesehatan masyarakat di Desa Sukabangun Dalam Kecamatan Delta Pawan Kabupaten Ketapang dalam hal ini untuk meningkatkan derajat kesehatan masyarakat.

\section{Metode Pelaksanaan}

Pengabdian ini dilakukan di desa suka bangun dalam dusun putri berkurung kecamatan deltapawan kabupaten Ketapang Indonesia. Kegiatan pengabdian dilakukan dari bulan juli sampai agustus 2021. Kegiatan meliputi Sosialisasi mengenai Jamban Sehat materi yang disampaikan berupa pengertian, manfaat dan indikator jamban sehat keluarga, kedua membangun jamban percontohan, ketiga Program Arisan Jamban Sehat (Anjas) untuk menginisiasi masyarakat membuat jamban di rumah masing-masing. keempat yakni pendampingan, dimaksudkan untuk membantu dan membimbing mitra kegiatan. 


\section{Hasil dan Pembahasan}

Kegiatan pengabdian difokuskan pada permasalahan mengenai sanitasi lingkungan masyarakat Desa Sukabangun Dalam melalui kegiatan berikut :

1. Koordinasi Kegiatan di Desa Sukabangun dalam dilaksanakan pada tanggal 26 Juli sampai 25 Agustus 2021. Kegiatan tahap awal yang dilaksanakan adalah melaksanakan lokakarya mini desa dengan tujuan menyampaikan paparan program kesehatan yang akan dilaksanakan di Desa Sukabangun Dalam. Lokakarya mini dilaksanakan pada Hari Kamis, 29 Juli 2021 yang dihadiri sebanyak 15 peserta baik dari unsur pemerintahan desa seperti kepala desa, kepala dusun dan masyarakat desa. Kegiatan lokakarya mini desa diperoleh kesepakatan bersama mengenai kegiatan program kesehatan jamban sehat percontohan yang akan dilaksanakan, jadwal, bentuk serta peran dari aparat dan masyarakat dalam kegiatan (Lihat Gambar 1).
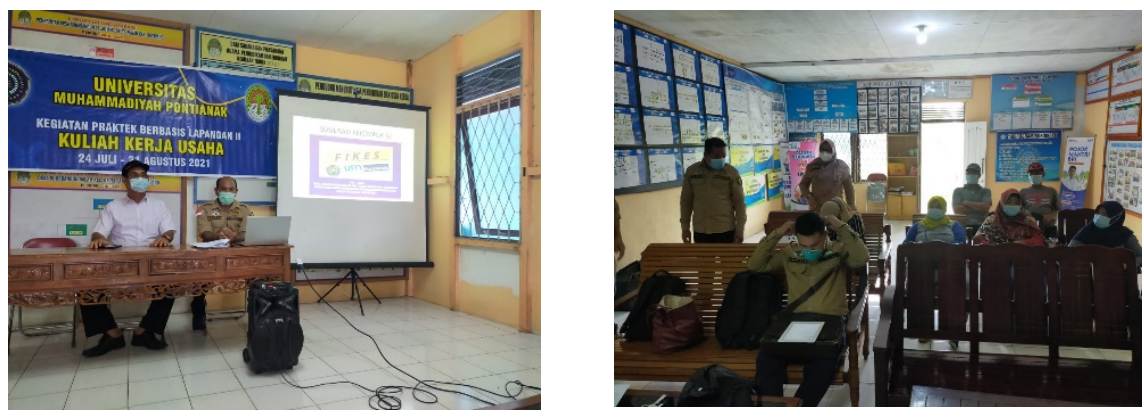

Gambar 1. Lokakarya Mini Desa Suka bangun Dalam

2. Sosialisasi dan Penyuluhan Kegiatan sosialisasi dan penyuluhan bertujuan agar masyarakat Desa mengetahui dan ikut serta secara aktif dalam program kesehatan salah satunya adalah mengikuti penyuluhan jamban sehat. Kegiatan dilaksanakan di Balai Desa Sukabangun Dalam. Sasaran kegiatan ini adalah kepala rumah tangga. Peserta penyuluhan sebanyak 20 warga. Materi penyuluhan yang disampaikan antara lain pengertian, manfaat dan indikator jamban sehat. Selain menyampaikan materi, narasumber juga melakukan diskusi dengan masyarakat terkait kebiasaan masyarakat yang masih melakukan BAB sembarangan. Risiko dari melakukan BAB adalah tercemarnya air sungai oleh kotoran manusia dan meningkatkan risiko terjadinya penyakit berbasis lingkungan. Titik Agustiyaningsih, Anggraini Dwi Kurnia, Retno Yunita Larasati, (2020) menyatakan bahwa Pengetahuan tentang jamban sehat dan lingkungan yang baik harus terus ditingkatkan untuk mengurangi perilaku BABS pada masyarakat.
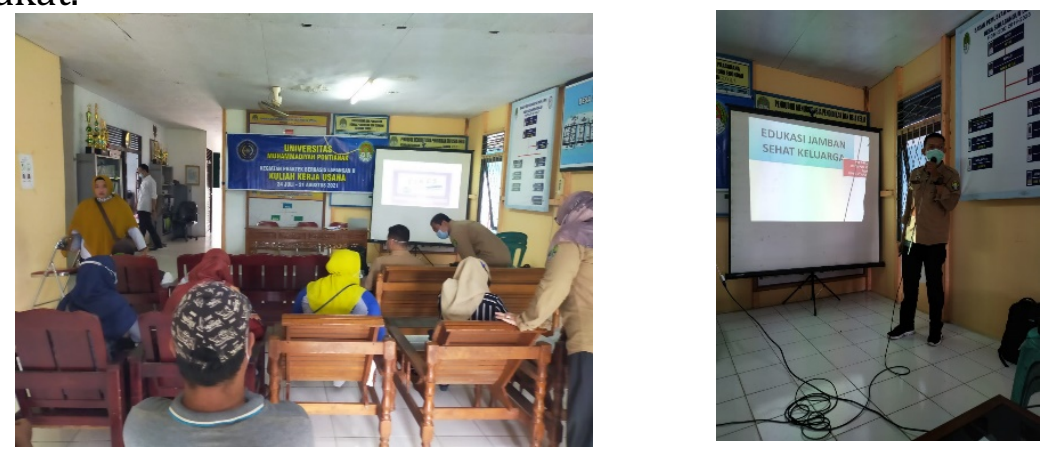

Gambar 2. Penyuluhan jamban sehat di Balai Desa Sukabangun Dalam 
3. Praktik Pembuatan Septic tank dan Jamban Sehat Percontohan. Kegiatan ini memanfaatkan jamban umum desa. Terdapat 2 jamban umum desa di lokasi yang berbeda. Untuk kegiatan jamban percontohan pemilihan lokasi jamban disesuaikan dengan kemudahan akses masyarakat. Jamban tersebut terletak di salah satu Surau. Proses pembangunan jamban dilakukan kurang lebih 1 minggu dengan melibatkan aparat desa dan masyarakat. Pihak desa dan masyarakat yang melakukan kesepakatan, bahwa jamban tersebut adalah jamban umum dan dapat dipergunakan masyarakat Desa Sukabangun Dalam khusunya Dusun Putri Bekurung, tidak hanya milik pribadi saja. Amalinda Kris Wijayanti, Laksmono Widagdo, Zahroh Shaluhiyah (2016) menyatakan bahwa Masyarakat agar ikut juga berpatisipasi melengkapi sarana dan prasarana penunjang jamban keluarga yang sudah dibantu oleh pemerintah atau pihak lain, supaya jamban tersebut menjadi jamban sehat yang layak.

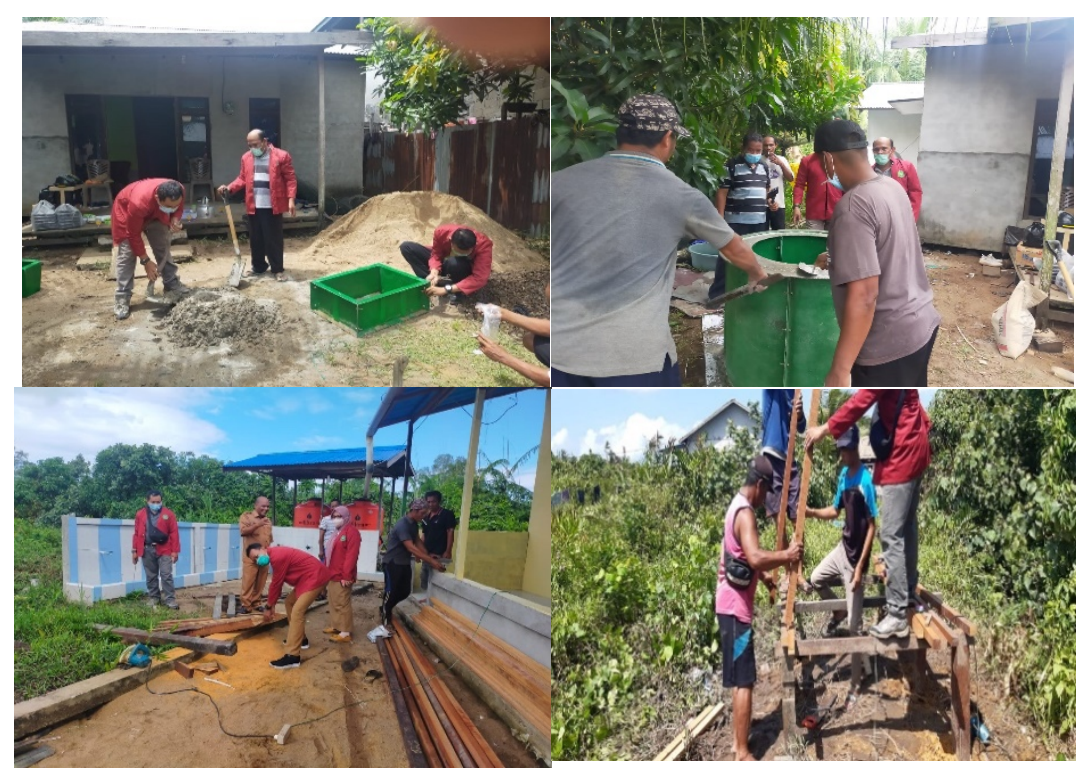

Gambar 3. Pembangunan jamban sehat di Desa Sukabangun Dalam

4. Arisan Jamban Sehat (Anjas)

Mekanisme pengelolaan Anjas dilakukan oleh seorang kader Kesehatan di setiap RT, dimana satu kelompok arisan jamban sehat terdiri dari sejumlah rumah tangga dalam satu wilayah RT, yang terdiri dari sekitar 50 rumah. Setiap rumah tangga kemudian mengumpulkan iuran sebesar Rp 2.000,-/hari. Lewat satu kelompok arisan, dapat terkumpul dana sebesar Rp 3 juta per bulan. Dengan demikian, rata-rata 1 jamban dapat dibangun di wilayah itu setiap bulannya. Marlenywati, Abduh Ridha, Hanum Mukti Rahayu (2019) bahwa komitmen membangun jamban percontohan desa bersama - sama yakni dengan berkomitmen mengikuti tabungan jamban (tanjan) sangat penting untuk mendukung adanya jamban sehat.

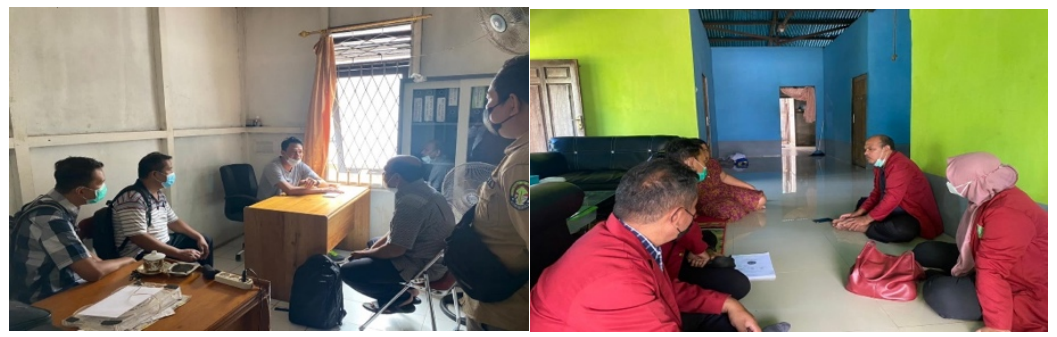

Gambar 4. Pembentukan kelompok Arisan Jamban Sehat (Anjas) 
5. Pendampingan

Pendampingan dimaksudkan untuk mengetahui penerapan ilmu dan praktek oleh masyarakat. Kegiatan yang mendapatkan respon positif dari masyarakat dan aparat desa di lakukan pendampingan agar terus berkelanjutan dengan membuat mou dan pembentukan kelompok jamban sehat dan arisan jamban. Di dalam MOU tersebut tertuang nama pengurus kelompok dan tugas nya yang di evaluasi berkala oleh kepala desa dan bekerja sama dengan kepala puskesmas Suka Bangun.

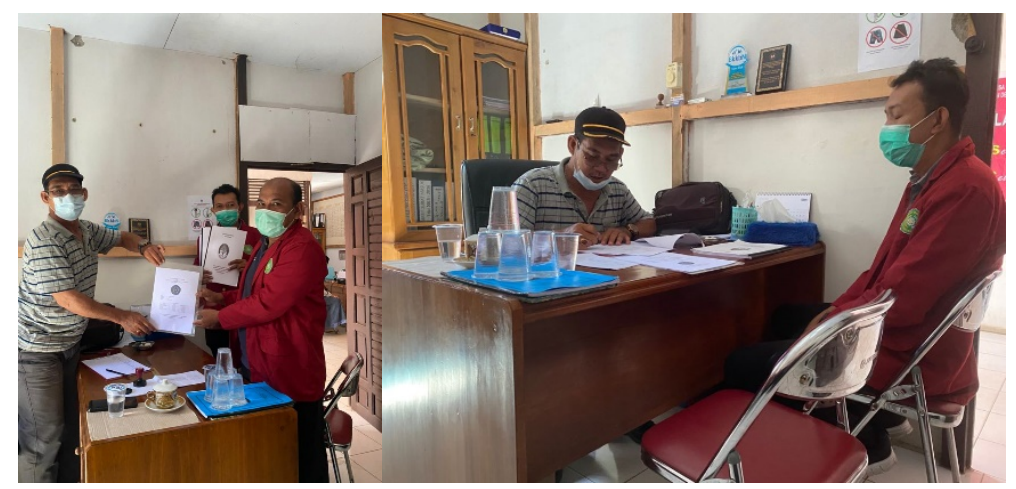

Gambar 5. Partisipasi aktif dari pihak Desa Suakabangun Dalam

\section{Kesimpulan}

Kegiatan pengabdian ini mendapatkan respon positif dan bermanfaat untuk masyarakat, khusus nya dusun putri berkurung desa suka bangun dalam. Kegiatan pengabdian memberikan dampak untuk peningkatan Kesehatan lingkungan terutama kepemilikan jamban sehat dan membuat jamban sehat dengan biaya terjangkau. Pemberdayaan yang dilakukan memiliki harapan untuk terus di lanjutkan dan dapat di terapkan pada dusun lain di Desa Suka Bangun Dalam.

\section{Ucapan Terimakasih}

Ucapan terima kasih disampaikan kepada Kepala Puskesmas Suka Bangun, Kepala Desa Suka Bangun Dalam, Rektor universitas Muhammadiyah Pontianak yang mendukung penuh terlaksananya program pengabdian ini. selanjutnya terima kasih kepada masyarakat desa yang mendukung penuh kegiatan ini

\section{Referensi}

Amalinda Kris Wijayanti, Laksmono Widagdo, Zahroh Shaluhiyah. Faktor-Faktor Yang Berhubungan Dengan Buang Air Besar Di Jamban Di Desa Gunungsari Kecamatan Pulosari Kabupaten Pemalang. Jurnal Kesehatan Masyarakat. 2016;1(1):23563346. http://ejournal-s1.undip.ac.id/index.php/ikm

Kemenkes RI. Profil Kesehatan Indonesia. Jakarta : Kementerian Kesehatan RI; 2021

Marlenywati, Abduh Ridha, Hanum Mukti Rahayu. Pemberdayaan Masyarakat Desa Mengkiang Melalui Program Jamban Percontohan. Jurnal Pengabdian Masyarakat JDINAMIKA. 2019;1(1):2503-1031. doi: 10.2504/j-dinamika.v4i1.1062.

Pemdes Sukabangun Dalam. Profil Desa Sukabangun Dalam. Ketapang : Pemerintahan Desa Sukabangun Dalam; 2020 
Puskesmas Sukabangun. Profil Kesehatan Wilayah Kerja. Ketapang : Pusat Kesehatan Masyarakat Sukabangun; 2020

Titik Agustiyaningsih, Anggraini Dwi Kurnia, Retno Yunita Larasati. Hubungan Pengetahuan tentang Jamban Sehat dan Lingkungan Fisik dengan Perilaku Buang Air Besar Sembarangan. Dunia Keperawatan. 2020;5(2):130-139. doi: $\underline{10.20527 / d k . v 8 i 1.7960}$ 